Tohoku J. Exp. Med., 1990, 161, Suppl., 49-60

\title{
Senile Dementia and Presenile Dementia
}

\author{
Shigenobu Nakamura* \\ Department of Neurology, Faculty of Medicine, Kyoto \\ University, Kyoto 606
}

\begin{abstract}
Nakamura, S. Senile Dementia and Presenile Dementia. Tohoku J. Exp. Med., 1990, 161, Suppl., 49-60- Neurotransmitters including acetylcholine, dopamine, norepinephrine, serotonin, GABA and vasopressin were examined in control subjects and patients with Alzheimer-type dementia, involving presenile and senile dementia. Neurotransmitters exhibited various mode of changes with aging. Abnormalities found in senile or presenile dementia were not always parallel to the age-related changes. These results suggest that Alzheimer-type dementia cannot be understood as an accerelated senescence, but other etiological factors might be introduced for the manifestation of the dementia. Moreover, the disturbance in neurotransmitters revealed a difference between presenile Alzheimer' $\mathrm{s}$ disease and senile dementia, indicating that further studies should be carried out taking the age of onset into consideration._- neurotransmitter; aging; presenile dementia; senile dementia
\end{abstract}

Dementia has become a serious problem in Japan. The prevalence rate in the population aged over 65 has been reported to be $4 \%$ in western Europe (MayerGross et al. 1969) or in the United States (Pfeiffer 1975). The incidence of dementia in the aged persons is roughly estimated to be about $5 \%$ Tokyo (Hasegawa et al. 1980). The frequency increases progressively with advance in age. The data suggest an explosively rapid increase in the incidence of dementia in the aged. It would certainly endanger the social and economical state in Japan in the near future. One of the effective ways to overcome the obstacle seems to elucidate the change in neurotransmitters in demented patients and to administer analogues or precursors of deficient neurotransmitters (Nakamura et al. 1984).

Since neurons are postmitotic and nondividing cells, the aging in the nervous system proceeds progressively and irreversively. The aging process also influences on neurotransmitters which regulate various nervous functions through synaptic transmission (Nakamura and Miyata 1986). Recently energetic attempts are undertaken to investigate abnormalities in neurotransmitters in age-related nervous diseases and to correct the abnormality through analogues or antagonists of neurotransmitters.

This paper describes age-related changes in choline acetyl-transferase (CAT),

*Present address and reprint requests to: Shigenobu Nakamura, Department of the Third Internal Medicine, Hiroshima University, School of Medicine, 1-2-3 Kasumi, Minamiku, Hiroshima 734, Japan. 
acetylcholinesterase (ACE), dopamine- $\beta$-hydroxylase (DBH), glutamic acid decarboxylase $(\mathrm{GAD})$, hydroxylase cofactor $\left(\mathrm{BPH}_{4}\right)$ activity in cerebrospinal fluid (CSF) and concentration of homovanillic acid (HVA) and 5-hydroxyindole-acetic acid (5-HIAA) in the CSF. $\mathrm{DBH}, \mathrm{ACE}, \mathrm{CAT}, \mathrm{GAD}$ and $\mathrm{BPH}_{4}$ activity and concentration of HVA, 5-HIAA and vasopressin were also studied in patients with presenile and senile dementia.

\section{Materials and Methods}

$\mathrm{L}-\left(4-{ }^{3} \mathrm{H}\right)$ phenylalanine, $\mathrm{L}-\left(1-{ }^{14} \mathrm{C}\right)$ glutamic acid and (acetyl- $\left.{ }^{3} \mathrm{H}\right)$ acetyl-CoA were obtained from New England Nuclear. Other chemicals were purchased from commercial sources.

CSF was taken at 9:00 AM from subjects who had been recumbent for at least two hours and $4 \mathrm{ml}$ of CSF had been used for examination of protein concentration and cell number.

All diagnoses were made from neurological and radiological findings by both psychiatrists and neurologists. Vascular dementia was diagnosed with reference to Hachinski's ischemic score (Hachinski et al. 1975) and the findings obtained with CT scan. In this study, obscure cases or those with a mixed type of Alzheimer-type and vascular dementia were excluded.

The activity of CAT was determined in various parts of autopsied brains which had been stored at $-80^{\circ} \mathrm{C}$ for two to ten months. A small portion of cerebral cortex was punched out and the substantia innominata was dissected into smaller pieces. The brain tissue was homogenized in saline (10 volume) and CAT activity was measured according to a method by Fonnum (1975), using ${ }^{3} \mathrm{H}$-acetyl CoA.

$\mathrm{ACE}$ activity in the CSF was determined by a colorimetric method by Ellman et al. (1961), using acetylthiocholine.

GAD activity was measured radiochemically by the method of Susz et al. (1966) with a modification.

Serum DBH activity was determined by a photometric assay (Nagatsu and Udenfriend 1972). DBH activity in the CSF was determined by a colorimetric assay at two different wave-lengths according to the method described by Kato et al. (1978).

Hydroxylase cofactor activity $\left(\mathrm{BPH}_{4}\right)$ in the $\mathrm{CSF}$ was detemined by a modification of the method described by Levine et al. (1979). CSF was incubated with ${ }^{3} \mathrm{H}$-phenylalanine, phenylalanine hydroxylase purified from rat liver, dihydrobiopterine quinonoid reductase purified from rat brain and NADH. The tritiated water was separated through a small column of Dowex-50: charcoal: Dowex-1 and the radioactivity was measured. Hydroxylase cofactor activity was calculated from that obtained with authentic 6methyltetrahydropteridine $\left(6 \mathrm{MPH}_{4}\right)$.

The concentration of HVA and 5-HIAA was determined either by fluorescence according to the method described by Korf and vanPraag (1971) or electrochemically after HVA and 5-HIAA were separated by high performance liquid chromatography (Zaczek and Coyle 1982).

AVP was examined in postmortem human brain by using a radioimmunoassay (Fujiyoshi et al. 1984). The RIA system was developed using less than $4 \mathrm{pg} /$ tube of ${ }^{125} \mathrm{I}-\mathrm{AVP}$ and shows low cross-reactivities to oxytocin and other neuropeptides. Nineteen brains were obtained from six cases of motor neuron disease, from four cases of cerebrovascular diseases, two cases with Parkinson's disease and 7 cases without a history of neurological or psychiatric disorders. Nine brains were obtained from patients with Alzheimer-type dementia. 


\section{Results}

\section{Choline acetyltransferase (CAT)}

CAT was remarkably reduced in all areas of the cerebral cortex of autopsied brains obtained from the patients with presenile Alzheimer's diease, in comparison with the age-matched control subjects. The prominent decrease was observed at Brodmann area $22(p<0.001)$, while at area 17 the reduction of the activity was less marked $(p<0.05)$. However, the decrease in CAT activity was less remarkable in autopsied brains of patients with a late-onset senile dementia. CAT activity was not decreased in the cerebral cortex of patients with Huntington's disease or PSP.

By dissecting the substantia innominata into small pieces, CAT activity could be measured in various parts of the nucleus. The highest activity was detected in he nucleus basalis of Meynert and correlated well with that at Brodmann area $22(p<0.01)$ and at area $17(p<0.05)$.

CAT activity was measured with the sample which was obtained by filtrating CSF with collodion bags to eliminate a CAT inhibitor. CSF CAT activity (y : $\mathrm{nmol} / \mathrm{hr} / 100 \mathrm{ml})$ decreased with increasing age $(\mathrm{x})(\mathrm{y}=21.75-0.253 \mathrm{x}, \mathrm{r}=$ $-0.504)$.

\section{Acetylcholinesterase $(A C E)$}

ACE in the CSF from patients with Alzheimer-type dementia and control subjects was analyzed by centrifugation on a sucrose density gradient and by column chromatography on Sephadex G-200. The sedimentation coefficient and molecular weight of CSF ACE were calculated as $10 \mathrm{~S}$ and 380,000, respectively, which corresponded to those of G4 isozyme in the brain. Other isozymes of ACE were not detected in the CSF of either patients with Alzheimer-type dementia or the control subjects.

Sufficient activity of ACE was observed in the CSF of a patient with familial pseudocholinesterase deficiency, although the pesudocholinesterase activity was not found either in the serum or in the CSF.

CSF ACE activity in control subjects increased with advancing age $(p<$ 0.02). ACE activity in the CSF was significantly lower in patients with presenile dementia, compared with age-matched control subjects $(p<0.001)$ (Fig. 1). However, ACE activity in the CSF showed a wide variation among patients of Alzheimer-type dementia with a late onset (senile dementia).

\section{Concentration of homovanillic acid (HVA) in CSF}

In the CSF of control subjects the concentration of HVA decreased slightly with increasing age $(\mathrm{r}=-0.29, p<0.05)$. The HVA concentration was significantly lower in the CSF of patients with Alzheimer-type dementia (26.0土 $15.0 \mathrm{ng} / \mathrm{ml}, p<0.01)$ and with vascular dementia $(32.3 \pm 20.6 \mathrm{ng} / \mathrm{ml}, p<0.05)$ 


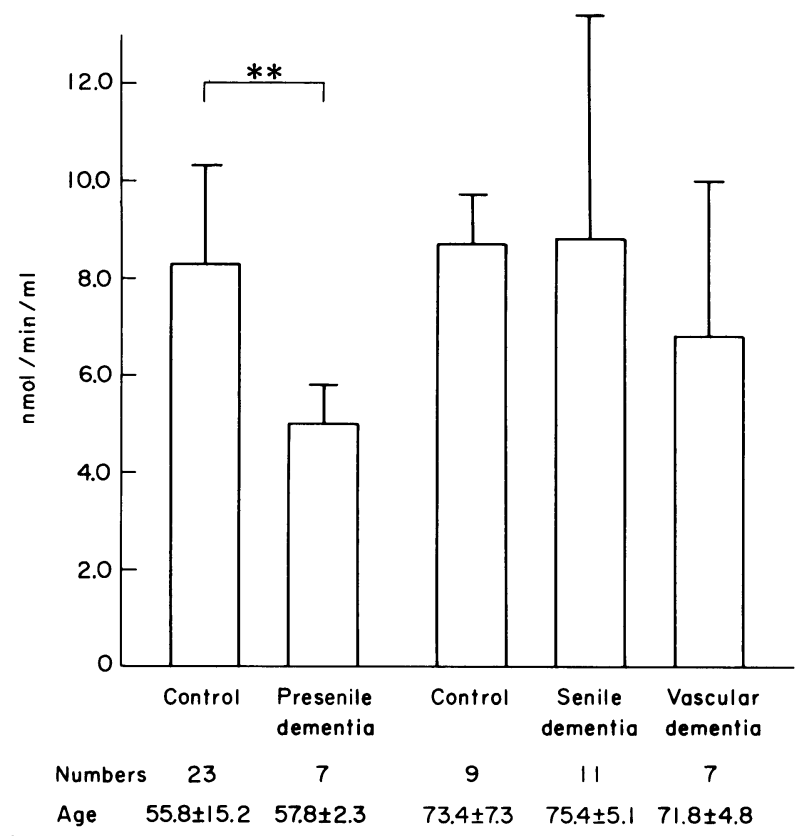

Fig. 1. Acetylcholinesterase activity in CSF of Alzheimer-type dementia and vascular dementia. Columns and bars indicate means and standard deviations. Number of cases and age (mean \pm S.D.) are also described. ${ }^{* *} p<0.01$.

than in that of control subjects $(44.8 \pm 16.1 \mathrm{ng} / \mathrm{ml})$.

The concentration of HVA was corrected for the CSF space, since the CSF space of demented patients is larger than that of normal control subjects and the HVA concentration in CSF may be diluted in Alzheimer-type dementia patients. The corrected HVA concentration was significantly lower in Alzheimer-type dementia patients $(p<0.01)$ than in control subjects, suggesting that the decrease in HVA concentration is due to lowered dopaminergic activity in the brain but not to the dilution of HVA in the CSF space.

When presenile and senile dementia were arbitrarily devided by the age of onset (65 years old), patients with presenile dementia (AD) showed a remarkable decrease in CSF HVA, while the decrease was not significant in patients with senile dementia (SD) (Fig. 2).

\section{Hydroxylase cofactor in $C S F$}

The $\mathrm{BPH}_{4}$ activity decreased in the CSF of control subiects as age increased $(\mathrm{r}=-0.35, p<0.05)$. $\mathrm{CSF}$ activity of $\mathrm{BPH}_{4}$ in Alzheimer-type dementia $(9.98 \pm$ $\left.2.296 \mathrm{MPH}_{4} \mathrm{eq} / \mathrm{ml}\right)$ was slightly lower than that in control subjects $(12.4 \pm 4.3$ $6 \mathrm{MPH}_{4} \mathrm{eq} / \mathrm{ml}, p<0.1$ ), but no difference was observed between vascular dementia $\left(11.8 \pm 1.36 \mathrm{MPH}_{4} \mathrm{eq} / \mathrm{ml}\right)$ and control subjects.

The concentration of HVA in the CSF of control subjects was well correlated 


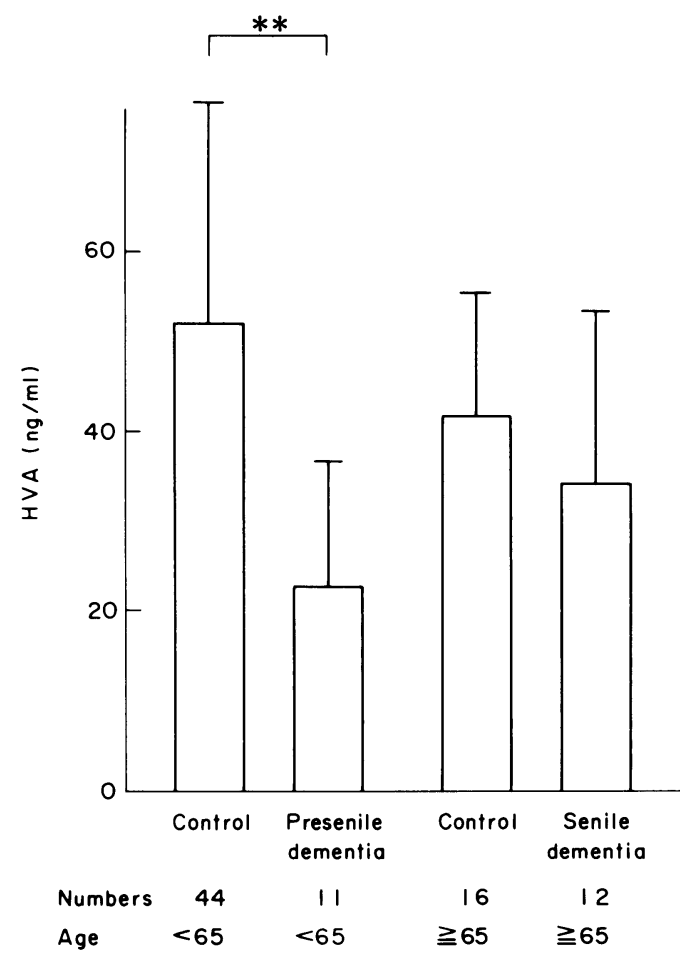

Fig. 2. Homovanillic acid (HVA) concentration in CSF of Alzheimer-type dementia. Columns and bars indicate means and standard deviations. Numbers of cases and age range are also described at the bottom. ${ }^{* *} p<0.01$.

with the $\mathrm{BPH}_{4}$ activity. However, the HVA concentration in Alzheimer-type dementia patients did not show any similar correlation.

\section{5-Hydroxyindoleacetic acid (5-HIAA) in $C S F$}

The concentration of 5-HIAA did not show an age-related change in the CSF of control subjects.

The 5-HIAA concentration was significantly lower in the CSF of patients with presenile Alzheimer's disease or with senile dementia than in that of control subjects (Fig. 3). The decrease in CSF 5-HIAA was more pronounced in patients with remarkable enlargement of cortical sulci revealed on CT scan. But the grade of dilatation of lateral ventricle did not correlate to the decrease in 5-HIAA concentration.

\section{Dopamine- $\beta$-hydroxylase in cerebrospinal fluid}

Dopamine- $\beta$-hydroxylase (DBH) activity in the CSF was much lower than that in serum, with no correlation shown between the $\mathrm{DBH}$ activities in serum and CSF. DBH activities in CSF obtained from patients with cervical spondylosis, 


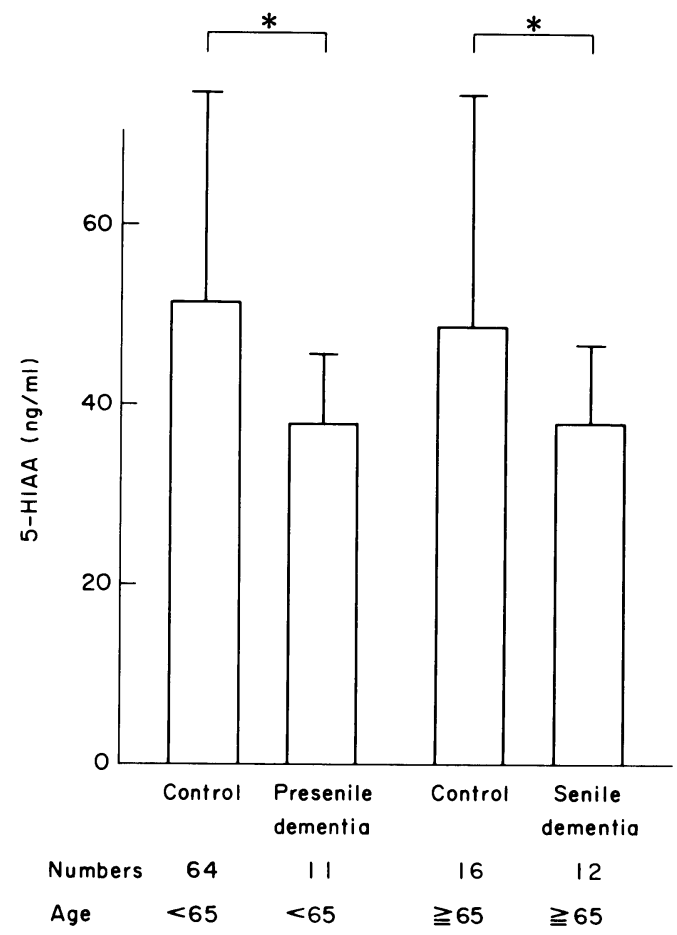

Fig. 3. 5-Hydroxyindoleacetic acid (5-HIAA) concentration in CSF of Alzheimer-type dementia. Columns and bars indicate means and standard deviations. Numbers of cases and age ranges are also described at the bottom. ${ }^{*} p<0.05$.

peripheral neuropathy oh myopathy did not differ with respect to the age of these subjects.

DBH activities in the CSF obtained from presenile, senile and vascular dementia patients were $1.81 \pm 1.30,1.49 \pm 0.74$ and $2.01 \pm 0.99 \mathrm{nmol} / \mathrm{ml} / \mathrm{hr}$, respectively. The $\mathrm{DBH}$ activity of the demented patients was lower than that of the control subjects described above $(5.48 \pm 3.57 \mathrm{nmol} / \mathrm{ml} / \mathrm{hr})$. Activities in control subjects showed a wide variation, but $\mathrm{DBH}$ activity was significantly reduced in the CSF of senile dementia patients $(p<0.05)$ (Fig. 4).

\section{Dopamine- $\beta$-hydroxylase in serum}

DBH activity in serum did not change until the eighth decade of life, but decreased markedly in the ninth decade.

Serum DBH activities in control subjects, presenile, senile and vascular dementia patients were $16.6 \pm 10.9,11.5 \pm 5.8,14.6 \pm 8.8$ and $14.7 \pm 9.5 \mathrm{nmol} / \mathrm{ml} /$ min, respectively. Serum DBH activity was significantly decreased in presenile dementia $(p<0.05)$, but not in senile and vascular dementia, although the mean $\mathrm{DBH}$ activity in control subjects was higher than in both senile and vascular 


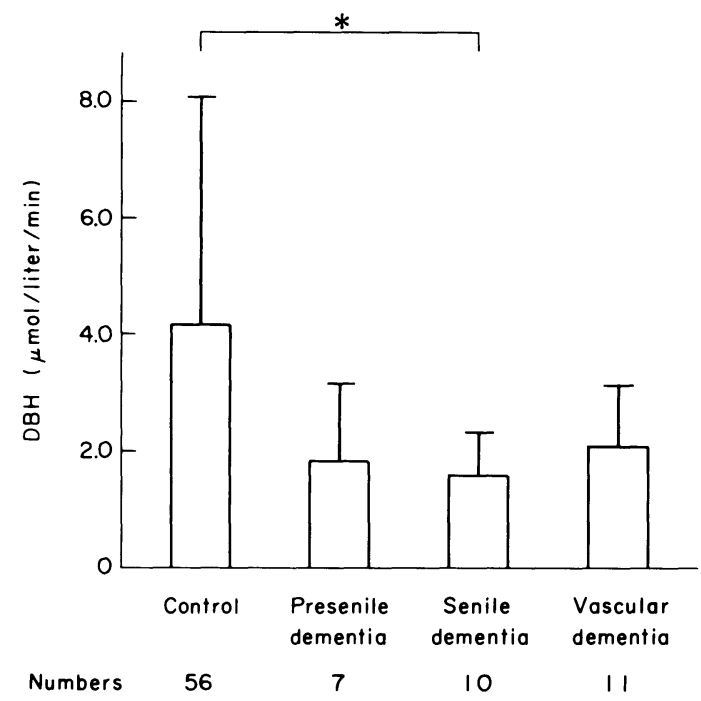

Fig. 4. Dopamine- $\beta$-hydroxylase (DBH) activity in CSF of Alzheimer-type dementia and vascular dementia. Columns and bars indicate means and s.E. ${ }^{*} p<0.05$.

dementia. The decrease in serum DBH in Alzheimer-type dementia patients was greater in the severely demented cases or in patients with marked cortical atrophy on CT scan.

Glutamic acid decarboxylase (GAD) in cerebrospinal fluid

The activity of GAD in the CSF decreased with the advance in age, reflecting the decrease in GAD activity in autopsied brains.

The GAD activity in the CSF was significantly reduced in patients with senile dementia. The GAD activity was corrected for the CSF volume and the corrected GAD activity was significantly lower in senile dementia than in control subjects.

\section{Vasopressin}

Arginine-vasopressin (AVP) concentrations in five cortical areas were measured post mortem in 9 patients with Alzheimer-type dementia and compared with an age-matched control group. In patients with senile dementia, AVP was significantly reduced in Brodmann area 4,7 and $10(p<0.05)$. In areas 17 and 22 , the detectability and the mean concentrations of AVP were also lower than those of control patients, although not significantly.

\section{Discussion}

Senile dementia with a late onset has been regarded as essentially identical to presenile Alzheimer's disease, since characteristic pathological findings of Alz- 
TABLE 1. Age-related changes and abnormalities of neurotransmitters in Alzheimertype dementia

\begin{tabular}{|c|c|c|c|c|c|}
\hline Neurons & Enzymes, Cofactor, Metabolites & Material & Aging & $\begin{array}{l}\text { Presenile } \\
\text { dementia }\end{array}$ & $\begin{array}{c}\text { Senile } \\
\text { dementia }\end{array}$ \\
\hline \multirow[t]{2}{*}{ Acetylcholine } & $\begin{array}{l}\text { Choline acetyltransferase } \\
\text { (CAT) }\end{array}$ & $\begin{array}{l}\text { Autopsied } \\
\text { brain }\end{array}$ & $\downarrow$ & $\downarrow \downarrow$ & $\downarrow$ \\
\hline & $\begin{array}{l}\text { Acetylcholinesterase } \\
\text { (ACE) }\end{array}$ & $\mathrm{CSF}$ & $\uparrow$ & $\downarrow$ & $\rightarrow$ \\
\hline \multirow[t]{2}{*}{ Dopamine } & $\begin{array}{l}\text { Homovanillic acid } \\
\text { (HVA) }\end{array}$ & $\mathrm{CSF}$ & $\downarrow$ & $\downarrow$ & \& \\
\hline & $\begin{array}{l}\text { Hydroxylase cofactor } \\
\left(\mathrm{BPH}_{4}\right)\end{array}$ & $\mathrm{CSF}$ & $\downarrow$ & $\downarrow$ & $\sim$ \\
\hline \multirow[t]{2}{*}{ Norepinephrine } & $\begin{array}{l}\text { Dopamine- } \beta \text {-hydroxylase } \\
\text { (DBH) }\end{array}$ & $\mathrm{CSF}$ & $\rightarrow$ & \& & $\downarrow$ \\
\hline & $\begin{array}{l}\text { Dopamine- } \beta \text {-hydroxylase } \\
\text { (DBH) }\end{array}$ & Serum & \& & $\downarrow$ & \& \\
\hline Serotonin & $\begin{array}{l}\text { 5-Hydroxyindoleacetic acid } \\
\text { (5-HIAA) }\end{array}$ & $\mathrm{CSF}$ & $\rightarrow$ & $\downarrow$ & $\downarrow$ \\
\hline \multirow[t]{2}{*}{ GABA } & $\begin{array}{l}\text { Glutamic acid decarboxylase } \\
\text { (GAD) }\end{array}$ & $\mathrm{CSF}$ & $\downarrow$ & $\sim$ & $\downarrow$ \\
\hline & $\begin{array}{l}\text { Glutamic acid decarboxylase } \\
\text { (GAD) }\end{array}$ & Serum & $\downarrow$ & $\sim$ & $\downarrow$ \\
\hline Vasopressin & $\begin{array}{l}\text { Arginine-vasopressin } \\
\text { (AVP) }\end{array}$ & $\begin{array}{l}\text { Autopsied } \\
\text { brain }\end{array}$ & $\rightarrow$ & $\sim$ & $\downarrow$ \\
\hline
\end{tabular}

$\uparrow, \rightarrow$, \&, $\downarrow, \downarrow \downarrow$ and $\sim$ indicate "increased, not changed, slightly decreased, decreased, remarkably decreased and not detected", respectively.

heimer's disease are also seen in senile dementia. Therefore, presenile and senile dementia have been dealt as a clinical entity called senile dementia of Alzheimer's type. However, various differences have been reported in both clinical and biochemical aspects. Results obtained in the present study are summarized in Table 1.

Acetylcholine has been known to participate in the consolidation of the memory (Drachmann 1977). Acetylcholine is synthesized from acetyl-CoA and choline by CAT. Acetyl-choline is further converted to acetic acid and choline by ACE. CAT seems to be related to a presynaptic function and ACE to a postsynaptic function.

The CAT activity has been reported to show an age-related decrease in the cerebral cortex of autopsied brain, especially in Brodmann area 21, 19 and 39 (McGeer and McGeer 1976). Consistent with the report, CSF CAT activity decreased with aging.

On the contrary, CSF ACE activity increased with aging. The reciprocal relation between CAT and ACE might be derived by a reactive change in the postsynaptic membrane, which would be introduced by presynaptic decrease in CAT. 
The most prominent decrease was observed in the superior temporal gyrus (Brodmann area 22), CAT activity of which correlated well with that of the nucleus basalis of Meynert.

The activity in autopsied brains was slightly lower in patients with senile dementia (mean age of onset: 84 years old) than age-matched control subjects.

Although cholinergic activity is reduced in Alzheimer-type dementia, it is not certain whether other neurons are involved in the pathogenesis of Alzheimer-type dementia.

Dopamine neuron plays a role in the regulation of motor performance and in the mental function such as memory or control of emotion (Udaka et al. 1984). HVA, the final metabolite of dopamine, has been measured in human CSF and used as an indicator of dopaminergic activity in the brain.

A decrease in HVA concentration in CSF was observed with increasing age, which could be due to the reduced activity of tyrosine hydroxylase, as has been reported by McGeer and McGeer (1976). However, the age-dependent change in HVA concentration was less remarkable than those observed in patients with presenile dementia.

The volume of the CSF space affects the concentration of HVA. In the present study, the CSF volume was calculated from CT scan film, and the HVA concentration was corrected by multiplying the dilution index. Even with the compensation for dilution effect, the concentration of HVA in the CSF was decreased in presenile dementia, indicating lowered dopaminergic activity in the brain. Similar results have been reported by Gottfries et al. (1969). Patients with presenile dementia sometimes show rigidity or gait disturbance as seen in Parkinson's disease, suggesting a dopaminergic disorder.

The rate-limiting enzyme in dopamine biosynthesis is tyrosine hydroxylase which requires $\mathrm{BPH}_{4}$ as a cofactor. The concentration of $\mathrm{HVA}$ and $\mathrm{BPH}_{4}$ correlated highly in the CSF of normal subjects, indicating that dopamine biosynthesis is regulated by $\mathrm{BPH}_{4}$. However, these two factors did not correlate highly in Parkinson's disease or senile dementia, suggesting that a decrease in HVA is not always due to a decrease in $\mathrm{BPH}_{4}$. A decrease in tyrosine hydroxylase apoenzyme seems to be more responsible for the reduction of dopamine.

Psychopharmacological examinations have revealed that serotonin would play a role in hallucination, arousal, depression or abnormal movements. Serotonin is metabolized to 5-HIAA which is measured as an indicator of serotonergic neuron in the CSF. The decrease in CSF 5-HIAA in presenile and senile dementia suggests a degeneration of serotonergic neuron in Alzheimer-type dementia.

Norepinephrine regulates not only motor activities and mental functions, but norepinephrine is also concerned with a sympathetic nervous function. Dopamine- $\beta$-hydroxylase (DBH) activity in the CSF is probably a marker enzyme of norepinephrine neurotransmission in the brain, while serum $\mathrm{DBH}$ is 
thought to reflect the systemic sympathetic activity (Noth and Mulrow 1976).

DBH activity in the CSF did not differ between young and old subjects, but it was significantly lower in senile dementia. These results are compatible to the findings that $\mathrm{DBH}$ activity in the brain tissue decreases in Alzheimer-type dementia (Mann et al. 1982) or with the hypothesis that norepinephrine innervation is involved in Alzheimer-type dementia (Bondareff et al. 1982).

Serum DBH activity decreased in control subjects over 80 years old and it was significantly lower in presenile dementia patients than in age-matched control subjects. The decrease in serum $\mathrm{DBH}$ presenile dementia patients was more marked in cases with a low score in mental tests or with severe brain atrophy on CT scan. It is likely that systemic sympathetic nervous dysfunction is also present in presenile dementia. This, in turn, may be related to the shortening of life expectancy in Alzheimer-type dementia.

Although the physiological role of GABA has not fully been elucidated, GABA concentration is known to decrease in the autopsied basal ganglia of Huntington's disease (Perry et al. 1973). GAD, the enzyme responsible for GABA synthesis, showed as age-dependent decrease, reflecting the age-related decrease in GABAnergic neuron in the brain. Low CSF GAD activity in Alzheimer-type dementia also suggests a reduced GABAnergic activity in the brain of Alzheimer-type dementia.

Vasopressin functions as an antidiuretic hormone, mainly regulating water and electrolyte metabolism. In the human body, AVP is synthesized in the hypothalamus, transported to the hypophysis and secreted into blood stream.

Recently, the hypothesis has been proposed that AVP serves in the consolidation of memory in addition to its antidiuretic function (DeWied 1965). AVP has been used clinically, especially for the therapy of dementia (Weingartner et al. 1981). However, neither the mechanism of action nor the localization of AVP in the brain had been clarified. Using a more sensitive method established in our laboratory (Fujiyoshi et al. 1984), the AVP was detected in $60 \%$ of the cerebral cortex of autopsied brains of control subjects, although the content was not high. However, AVP was detected less frequently in the cortex of patients with Alzheimer-type dementia. No age-related change was observed in AVP content in the cortex.

The results obtained in this study indicate that in addition to the cholinergic system, other neurotransmitters such as dopamine, norepinephrine, serotonin, GABA and vasopressin are associated with the pathogenesis of Alzheimer-type dementia. Considering diverse changes, a more effective program should be devised besides acetylcholine therapy.

\section{Acknowledgments}

I wish to thank Dr. E. Otomo,, Yokufukai Geriatric Hospital; Dr. M. Ogawa, Hamamatsu Rosai Hospital ; Prof. T. Ashiwara, Kyoto Prefecture Medical College ; Dr. M. 
Kato, Biwako Yoikuin Hospital, Otsu for collecting the autopsied brains and Drs. K. Koshimura, T. Kato, S. Yamao, S. Iijima, H. Nagata, S. Miyata, K. Fujiyoshi, K. Okamoto, H. Suga and M. Kameyama for technical helps and scientific advices.

\section{References}

1) Bondareff, W., Mounjoy, C.Q. \& Roth, M. (1982) Loss of neurons of the adrenergic projection to cerebral cortex (nucleus locus coeruleus) in senile dementia. Neurology, 32, $164-168$.

2) DeWied, D.C. (1965) The influence of the posterior and intermediate lobe of the pituitary and pituitary peptides on the maintenance of a conditioned avoidance response in rats. Int. J. Neuropharmacol., 4, 157-167.

3) Drachmann, D.A. (1977) Memory and cognitive function in man ; Does the cholinergic system have a specific role? Neurology, 27, 783-790.

4) Ellman, G.L., Courtney, D.K., Andres, V., Jr. \& Featherstone, R.M. (1961) A new and rapid colorimetric determination of acetyl-cholinesterase activity. Biochem. Pharmacol., 7, 88-95.

5) Fonnum, F.A. (1975) A rapid radiochemical method for the determination of choline acetyltransferase. J. Neurochem., 24, 407-409.

6) Fujiyoshi, K., Suga, H., Okamoto, K., Nakamura, S. \& Kameyama, M. (1984) Regional distribution of arginine-vasopressin in post-mortem human brain. Clin. Neurol., 24, 467-471. (in Japanese with English abstract)

7) Gottfries, C.G., Gottfries, I. \& Roos, B.E. (1969) The investigation of homovanillic acid in the human brain and its correlation to senile dementia. Br. J. Psychiatry, 115, 563-574.

8) Hachinski, V.C., Iliff, L.D., Zihlka, E., DuBoulay, G.H., McAllister, V.L., Marshall, J., Russel, R.W.R. \& Symon, L. (1975) Cerebral blood flow in dementia. Arch. Neurol., 32, 632-637.

9) Hasegawa, K., Homma, A., Yook, M., Amamoto, H., Sato, H., Itami, Y., Asakura, M., Tashiro, T., Imai, Y., Tsukamoto, T., Iwai, H. \& Aoba, A. (1980) A gerontopsychiatric 5 years follow-up study on age-related dementia reading in the community. Jap. J. Geriat., 17, 630-638. (in Japanese with English abstract)

10) Levine, R.A., Kuhn, D.M. \& Lovenberg, W. (1979) The regional distribution of hydroxylase cofactor in rat brain. $J$. Neurochem., 32, 1575-1578.

11) Kato, T., Wakui, Y. \& Nagatsu, T. (1978) An improved dual-wave length spectrophotometric assay for dopamine- $\beta$-hydroxylase. Biochem. Pharmacol., 27, 829-831.

12) Korf, J. \& vanPraag, H.M. (1971) Amine metabolism in the human brain. Brain Res., 35, 221-230.

13) Mann, M.D., Yates, P.O. \& Hawkes, J. (1982) The noradrenergic systems in Alzheimer and multi-infarct dementias. J. Neurol. Neurosurg. Psychiatry, 45, 113-119.

14) Mayer-Gross, W., Slater, E. \& Roth, M. (1969) Clinical Psychiatry, Baillière, Tindall and Cassel, London.

15) McGeer, E. \& McGeer, P.L. (1976) Neurotransmitter metabolism in the aging brain. In: Neurobiology of Aging, edited by R.D. Terry \& S. Gershon, Raven Press, New York, pp. 389-403.

16) Nagatsu, T. \& Udenfriend, S. (1972) Photometric assay of dopamine- $\beta$-hydroxylase activity in human blood. Clin. Chem., 18, 980-983.

17) Nakamura, S. \& Miyata, S. (1986) Aging and neurotransmitters. Jpn. J. Med., 25, 87-89.

18) Nakamura, S., Koshimura, K., Kato, T., Yamao, S., Iijima, S., Nagata, H., Miyata, S., Fujiyoshi, K., Okamoto, K., Suga, H. \& Kameyama, M. (1984) Neurotransmitters in dementia. Clin. Therap., 7, 18-34.

19) Noth, R.H. \& Mulrow, P.J. (1976) Serum dopamine- $\beta$-hydroxylase as an index of 
sympathetic nervous system activity in man. Circ. Res., 38, 2-5.

20) Perry, T.L., Hansen, S. \& Kloster, M. (1973) Huntington's chorea : Deficiency of $\gamma$-amino-butyric acid in brain. $\quad N$. Engl. J. Med., 288, 337-342.

21) Pfeiffer, E. (1975) A short portable mental status questionnaire for the assessment of organic brain deficit in elderly patients. J. Am. Geriatr. Soc., 23, 433-441.

22) Susz, J.P., Harber, B. \& Roberts, E. (1966) Purification and some properties of mouse brain L-glutamic decarboxylase. Biochemistry, 5, 2870-2877.

23) Udaka, F., Yamao, S., Nagata, H., Nakamura, S. \& Kameyama, M. (1984) Pathological laughing and crying treated with levodopa. Arch. Neurol., 41, 1095-1096.

24) Weingartner, H., Kaye, W., Gold, P., Smallberg, S., Peterson, R., Gillin, J.C. \& Ebert, M. (1981) Vasopressin treatment of cognitive dysfunction in progressive dementia. Life Sci., 29, 2721-2726.

25) Zaczek, P. \& Coyle, J.T. (1982) Rapid and simple method for measuring biogenic amines and metabolites in brain homogenates by HPLC-ECD. J. Neural. Transm., 53, 1-5. 